\title{
MANEJO ODONTOLÓGICO EM PACIENTE COM AMILOIDOSE SUBMETIDO A TRANSPLANTE AUTÓLOGO DE CÉLULAS-TRONCO HEMATOPOIÉTICAS - RELATO DE CASO
}

\author{
Dental management in patient with amyloidosis underwent to autologous \\ hematopoietic stem cell transplantation - Case report \\ Walmyr Ribeiro de Mello ${ }^{1}$, Paulo Sérgio da Silva Santos ${ }^{2}$, Ricardo Rabello Chiattone ${ }^{3}$, Frederico Buhatem Medeiros ${ }^{1}$, \\ Karin Sá Fernandes ${ }^{1}$, Vania Tietsche de Morais Hungria ${ }^{3}$, Fabio Luiz Coracin ${ }^{4}$.
}

\section{RESUMO}

A amiloidose é caracterizada pela deposição extracelular de uma proteína fibrilar insolúvel de cadeia pesada em órgãos e tecidos e pode ser classificada como primária ou secundária. Relato de Caso: Um paciente do gênero masculino, 62 anos, apresentou queixa de dor lombar acompanhada por macroglossia. A biópsia de língua confirmou o diagnóstico de amiloidose. O tratamento instituído foi de transplante autólogo de células-tronco hematopoéticas. O exame físico intraoral no período do transplante mostrou macroglossia, lábios e mucosa desidratados, sem lesões ulceradas em toda a mucosa oral e linfadenopatia submandibular. Protocolo de higiene oral foi instituído, baseado em uso de escova extra-macia e creme dental à base de clorexidina, associado a bochechos, HPA-Lanolina para a hidratação dos lábios e hidratante gel para mucosa oral. Laserterapia de baixa potência para mucosite oral teve início em D 0 até $D+11$. Escala Visual Analógica foi utilizada para quantificar o escore de dor / desconforto da língua e orofaringe. A pontuação descrita pelo paciente na língua antes da laserterapia (variação de 0-6) e depois da laserterapia (variação de 0-3). O paciente atingiu o maior grau de mucosite oral (Grau 1 - OMS). Conclusões: O diagnóstico de amiloidose com manifestação bucal e a aplicação do protocolo de higiene bucal na prevenção de mucosite oral durante o transplante foram eficazes no controle e redução das manifestações bucais durante o transplante e tem recomendação para aplicação.

Descritores: Amiloidose; Transplante de Células-Tronco Hematopoiéticas; Mucosite.

\footnotetext{
Instituições:

${ }^{1}$ Equipe de Odontologia Hospitalar do Hospital Samaritano - São Paulo/SP

2 Departamento de Estomatologia da Faculdade de Odontologia de Bauru/USP - Bauru/SP

${ }^{3}$ Serviço de Oncohematologia do Hospital Samaritano - São Paulo/ SP

${ }^{4}$ Faculdade de Odontologia da Universidade Nove de Julho - São Paulo/SP
}

\section{Correspondência:}

Paulo Sérgio da Silva Santos

Al. Dr. Octávio Pinheiro Brisolla, 9-75 - CEP 17012-901- Bauru/SP

Tel. (14) 3235-8000

E-mail: paulosss@usp.br

Recebido em: 01/09/2014

Aceito em: 30/09/2014

\section{INTRODUÇÃO}

A amiloidose é uma doença rara, com deposição de proteína amilóide em tecidos e órgãos, tais como coração, fígado e rins, classificada de acordo com o tipo de proteína amilóide fibrils. ${ }^{1}$ É atualmente classificada em três tipos: (1) primária, quando ocorre isoladamente ou associada à doença clonal linfoide; (2) secundária, adquirida, ou reativa, que na maioria das vezes ocorre como uma complicação de infecções ou inflamações crônicas que levam à produção de proteínas de fase aguda no fígado reactivos; e (3) hereditária. ${ }^{2,3}$

A forma mais comum de amiloidose sistêmica é a amiloidose de cadeia leve, também chamada amiloidose primária ou mieloma múltiplo-associado. ${ }^{1}$ 
Os sinais e sintomas associados com a amiloidose são manifestações não específicas, tais como a fadiga ou a anorexia e proteinúria comum, como o primeiro sinal associado com doença sistêmica com comprometimento renal. $^{2}$

O diagnóstico é realizado por aspectos histológicos em associação aos resultados clínicos e o prognóstico é muito favorável para pacientes com a doença localizada. ${ }^{4}$ Nesses casos associados com complicações sistêmicas, reduz significativamente a sobrevida, com não mais de dois anos de tratamento. ${ }^{5}$

$\mathrm{Na}$ amiloidose primária, o tratamento compreende melfalano intravenoso mais quimioterapia em altas doses e transplante de células estaminais ou melfalano e prednisolone. ${ }^{6}$ Abordagens terapêuticas satisfatórias com várias drogas têm sido usadas para a amiloidose, tais como: melfalano (ou ciclofosfamida) + prednisona; colchicina; melfalano + prednisona + colchicina; outros (VAD Penicinilamina $D$, vitamina $E$, talidomida, interferon alta) e Transplante de Células-Tronco Hematopoiéticas (TCTH). ${ }^{6-8}$

O objetivo deste relato de caso é mostrar a participação da odontologia no diagnóstico da amiloidose com manifestação bucal e a abordagem odontológica de cuidados bucais durante o TCTH.

\section{Relato de Caso}

Paciente de 62 anos, do gênero masculino, queixouse de dor lombar, edema progressivo dos membros inferiores e aumento de tamanho da língua. A fim de excluir o diagnóstico do mieloma múltiplo, CT-scan e biópsia de medula óssea foram realizados, com resultados negativos. A triagem das funções hepáticas e renais e avaliação do miocárdio foram normais. Nenhuma alteração foi revelada na biópsia do intestino. No entanto, a biópsia da língua revelou a presença de proteínas amilóides, confirmada pela coloração congo vermelho.

O paciente foi encaminhado para o TCTH autólogo e o regime de condicionamento foi constituído de melfalano $200 \mathrm{mg} / \mathrm{m} 2$ no D-2 e D-1. Houve toxicidade de grau-I de mucosite oral de acordo com a OMS (Organização Mundial da Saúde). (Figura 1)

O protocolo de higiene oral consistiu do uso de escova dental extra macia e creme dental à base de clorexidina, enxaguante bucal de clorexidina $0,12 \%$ aquosa, HPAlanolina para os lábios ressecados e gel hidratante para a mucosa oral desidratada. Laserterapia de Baixa Potência (LBP) foi utilizada para prevenir a mucosite oral (InGaAIP. 630-690 nm, $100 \mathrm{~mW}$ ) desde D0 até D
+11 após o transplante. A dor devido à mucosite oral foi graduada, utilizando uma Escala Analógica Visual (VAS) antes e após a sessão de LBP, para quantificar a dor/desconforto da língua e orofaringe. A pontuação apontada pelo paciente na língua antes do LBP (0-6) e depois da $\operatorname{LBP}(0-3)$. O paciente atingiu o maior grau de mucosite oral (Grau 1 - OMS).

Figura 1 - Aspecto clínico da boca em mucosite oral grau I (OMS)

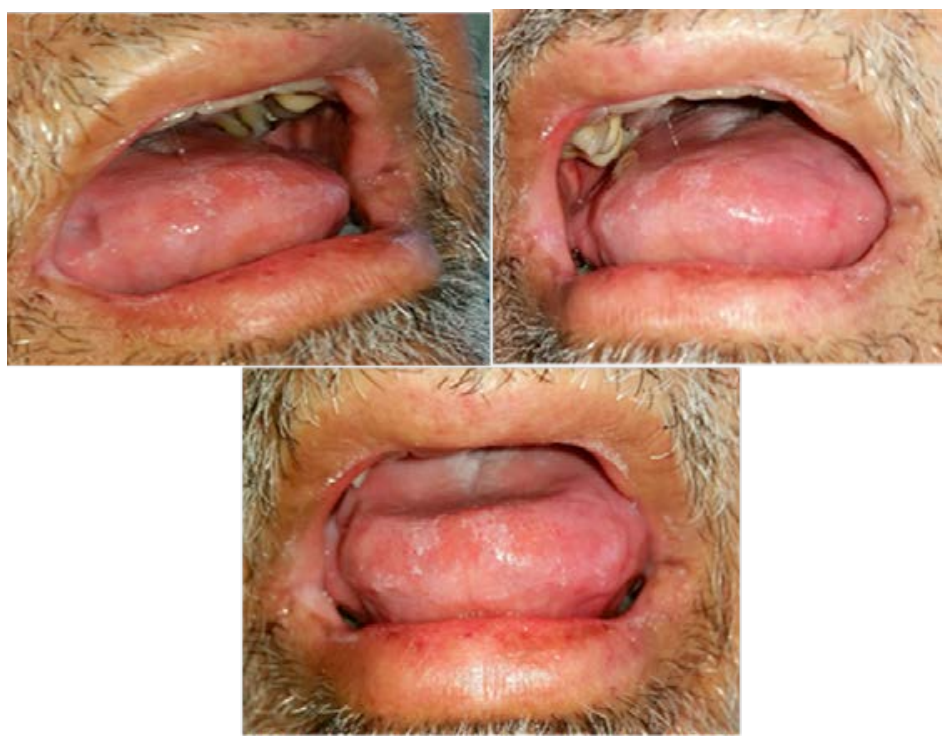

\section{DISCUSSÃO}

Neste relato de caso, a manifestação primária de amiloidose foi inicialmente confundida com mieloma múltiplo e foi investigada para diagnóstico diferencial.

Devido aos resultados negativos para o mieloma múltiplo, biópsia de intestino e de língua, foi realizada e utilizada coloração congo vermelho, confirmando presença de proteínas amilóides na língua, o que permitiu o estabelecimento do diagnóstico de amiloidose.

A amiloidose pode ser classificada em forma sistêmica e localizada (Tabela 1). A ocorrência de neuropatias periféricas é mais comumente associada com amiloidose familiar e insuficiência demência/cognitiva para depósitos de amilóide no cérebro. Órgãos como o fígado, rim, baço e coração, podem sofrer aumento de tamanho no caso de amiloidose primária e secundária, o que não ocorre na amiloidose familiar e amiloidose associada à doença de Alzheimer. ${ }^{6}$

Em todas as formas de amiloidose sistêmica, a evolução do paciente geralmente é contínua, grave e fatal. ${ }^{4} \mathrm{O}$ paciente deste relato de caso não apresentava 
Walmyr Ribeiro de Mello, Paulo Sérgio da Silva Santos, Ricardo Rabello Chiattone, Frederico Buhatem Medeiros, Karin Sá Fernandes, Vania Tietsche de Morais Hungria, Fabio Luiz Coracin

Tabela 1 - Classificação das amiloidoses

\begin{tabular}{|c|c|c|c|c|}
\hline \multirow{7}{*}{$\begin{array}{l}\text { Formas } \\
\text { Sistêmicas }\end{array}$} & Proteína Precursora & Proteína Amilóide & Doença Relacionada & Órgãos Afetados \\
\hline & Cadeia Leve & $\mathrm{AL}$ & AMILOIDOSE AL & $\begin{array}{l}\text { Rim, Fígado, TGI, Baço, Tecidos Moles, } \\
\text { SN Periférico, Tireóide e Adrenal }\end{array}$ \\
\hline & $\begin{array}{l}\text { Amilóide Sérico } \\
\text { (SAA) }\end{array}$ & AA - AA Hereditário & $\begin{array}{l}\text { Amiloidose AA FFM, TRAPS, } \\
\text { Muckle Wells }\end{array}$ & $\begin{array}{l}\text { Rim, Fígado, TGI, Baço, Tecidos Moles, } \\
\text { SN Autônomo, Tireóide }\end{array}$ \\
\hline & Cadeia Pesada & $\mathrm{AH}$ & $\begin{array}{c}\text { Doença de Células Plasmáticas } \\
\text { Não Mieloma }\end{array}$ & Rim, Coração e Nervos \\
\hline & $\begin{array}{l}\text { TTR, Apo AI e AII, } \\
\text { fa, LIS, GEL, CIS }\end{array}$ & $\begin{array}{l}\text { ATTR, AAAPoAl, Aapo- } \\
\text { All, AfibA, Alis, Agel, Acis }\end{array}$ & Amiloidose Familial & Variável, Rins em ApoAl, ApoAll, Lis \\
\hline & TTR (selvagem) & ATTR & Amiloidose Senil & Coração e Tecidos Moles \\
\hline & B2 micro-Globulina & $\mathrm{AB} 2 \mathrm{M}$ & Amiloidose de Diálise & Tecido Periarticular e osso \\
\hline \multirow{6}{*}{$\begin{array}{c}\text { Formas } \\
\text { Localizadas }\end{array}$} & Amilina & AIAPP & $\begin{array}{l}\text { Diabetes melito Tipo II e } \\
\text { Insulinoma }\end{array}$ & Pâncreas \\
\hline & Calcitonina & ACal & Carcinoma medular de Tireóide & Tireóide \\
\hline & Fator Natriurético Atrial & AANF & Amiloidose Atrial & Coração \\
\hline & Proteína AB & $\mathrm{AB}$ & $\begin{array}{l}\text { Doença de Alzheimer } \\
\text { Síndrome de Down }\end{array}$ & Cérebro \\
\hline & Prolactina & APro & Prolactinoma & Pituitária \\
\hline & Proteína Prion & AprP & $\begin{array}{l}\text { Doença de Creutzfeld-Jacob } \\
\text { Enecefalopatia Espongiliforme }\end{array}$ & Cérebro \\
\hline
\end{tabular}

neuropatia periférica e o diagnóstico foi feito com base na biópsia de língua. Nenhuma outra característica clínica de amiloidose foi vista.

O tipo localizado de amiloidose em língua é rara, ocorre de forma isolada e inesperadamente, sem alterações clínicas superiores ou associada a doenças sistêmicas. ${ }^{9}$ As lesões da amiloidose são incomuns na cavidade oral, embora os sítios geralmente afetados da cabeça e pescoço sejam a laringe e tireóide. Os locais mais frequentes na boca são: língua, lábios e mucosa oral. ${ }^{10-12}$ O paciente deste relato realizou biópsia de língua e as características microscópicas confirmaram os depósitos de amilóide na coloração vermelho Congo.

Os cuidados bucais durante o TCTH para prevenção e controle da mucosite oral baseados em redução da microbiota bacteriana bucal e LBP ${ }^{13}$ são efetivos e estão baseados em protocolos mundiais, sendo utilizados de forma rotineira no serviço de odontologia junto à equipe de TCTH da instituição onde o caso foi conduzido.

O diagnóstico precoce foi importante neste caso, levando ao tratamento imediato com altas doses de quimioterapia seguida de TCTH. O paciente está sob controle e sem complicações, no seguimento de 20 meses.

\section{CONCLUSÃO}

Este caso está relacionado com a importância do diagnóstico precoce da amiloidose primária realizada por equipe interdisciplinar. As toxicidades bucais decorrentes do TCTH foram bem controladas, de acordo com os protocolos de cuidados orais utilizados. 


\section{ABSTRACT}

Amyloidosis is characterized by extracellular deposition of a fibrillary pathological or insoluble protein in organs and tissues, and it can be classified as primary or secondary. Case Report: A male 62 years old patient presented complaint of back pain followed by macroglossia. The biopsy of the tongue confirmed the amyloidosis diagnosis. The treatment was autologous transplant of hematopoietic stem cells. The intraoral physical examination during the transplant period showed macroglossia, dehydrated lips and mucosa with no ulcerated lesions in all the oral mucosa and submandibular lymph node. A protocol for oral hygiene was instituted based on the use of 12,000 bristles brush and chlorhexidine-base toothpaste to $0.12 \%$ chlorhexidine rinses $0.12 \%$, HPA-Lanolin to hydrate the kips and moisturizing gel for the oral mucosa followed by low power lasertherapy for the oral mucositis daily from D0 to D+11. The Visual Analogical Scale was used to quantify the tongue and oropharyngeal pain/discomfort score. The patient described a score in the tongue before the lasertherapy (0-6 range) and after the lasertherapy (0-3 range). The patient reached the highest score of oral mucositis (L1 - WHO). Conclusions: The diagnosis of amyloidosis with oral manifestations and applying the oral hygiene protocol to prevent the oral mucositis along transplant were effective in controlling and reducing oral during the transplant, and such application is recommended.

Keywords: Amyloidosis; Hematopoietic Stem-Cell Transplantation; Mucositis.

\section{REFERÊNCIAS}

1. Dhodapkar M, Belloti V, Merlini G. Hematology: Basic principles and practice. 3rd ed. Philadelphia: Churchill Livingstone; 2000. p. 1416-32.

2. Seldin D, Sanchorawala V. Adapting to AL amyloidosis. Haematologica. 2006;91(12):1591-5.

3. Lachmann HJ, Goodman HJ, Gilbertson JA, Gallimore JR, Sabin CA, Gillmore JD, et al. Natural history and outcome in systemic AA amyloidosis. N Engl J Med. 2007;356(23):2361-71.

4. Rubin E, Gorstein F. Patologia: bases clinicopatológicas da medicina. Rio de Janeiro: Guanabara Koogan; 2006. $4^{\text {a }}$ Ed.

5. Fahrner KS, Black CC, Gosselin BJ. Localized amyloidosis of the tongue: a review. Am J Otolaryngol. 2004;25:186-9.

6. Sipe J, Cohen A. Harrison Medicina interna. $16^{\mathrm{a}}$ ed. Rio de Janeiro: Mcgraw-hill; 2006. V.2, p. 2123-8.

7. Dispenzieri A, Lacy MQ, Katzmann JA, Rajkumar SV, Abraham RS, Hayman SR, et al. Absolute valuesof immunoglobulin free light chains are prognostic in patients with primary systemic amyloidosis undergoing peripheral blood stem cell transplantation. Blood. $2006 \mathrm{Apr}$ 15;107(8):3378-83.
8. Gertz MA, Lacy MQ, Dispenzieri A, Hayman SR, Kumar SK, Leung $N$, et al. Effect of hematologic response on outcome of patients undergoing transplantation for primary amyloidosis: importance of achieving a complete response. Haematologica. 2007;92:1415-8.

9. Xavier SD, Bussoloti Filho I, Mulller H. Macroglossia decorrente de amiloidose sistêmica: relato de caso e revisão de literatura. Revista Brasileira de Otorrinolaringologia. 2004;70(5):715-9.

10. Asaumi JI, Yanagi Y, Hisatomi M, Konouchi H, Kishi K. CT and MR imaging of localized amyloidosis. European Journal of Radiology. 2001;39:83-

11. Balatsouras DG, Eliopoulos P, Assimakopoulos D. Primary local amyloidosis of the palate. Otolaryngol Head Neck Surg. 2007;137:3489.

12. Pentenero M, Bonino LD, Tomasini C. Localized oral amyloidosis of the palate. Amyloid. 2006;13:42-6.

13. Santos PSS, Messaggi AC, Mantesso A, Magalhães MHCG. Mucosite oral: perspectivas atuais na prevenção e tratamento. RGO 2009;57(3):339-44. 